Cahiers de civilisation médiévale

\title{
Collectif, Crusading Europe: Essays in Honour of Christopher Tyerman
}

Carol Sweetenham

\section{(2) OpenEdition}

1 Journals

Édition électronique

URL : https://journals.openedition.org/ccm/5380

DOI : $10.4000 / \mathrm{ccm} .5380$

ISSN : 2119-1026

Éditeur

Centre d'études supérieures de civilisation médiévale/Université de Poitiers

\section{Édition imprimée}

Date de publication : 1 décembre 2020

Pagination : 276-278

ISBN : 978-2-490783-07-6

ISSN : 0007-9731

\section{Référence électronique}

Carol Sweetenham, "Collectif, Crusading Europe: Essays in Honour of Christopher Tyerman », Cahiers de civilisation médiévale [En ligne], 252 | 2020, mis en ligne le 02 décembre 2020, consulté le 09 décembre 2022. URL : http://journals.openedition.org/ccm/5380 ; DOI : https://doi.org/10.4000/ccm.5380

\section{c) (†) $\ominus$}

Creative Commons - Attribution - Pas d'Utilisation Commerciale - Pas de Modification 4.0 International - CC BY-NC-ND 4.0

https://creativecommons.org/licenses/by-nc-nd/4.0/ 
Crusading Europe: Essays in Honour of Christopher Tyerman, G. E. M. LipPIATT et Jessalynn L. BiRd (éd.), Turnhout, Brepols (Outremer, 8), 2019.

L'œuvre de Christopher Tyerman nous offre des perspectives très variées et riches sur les croisades. Nous lui devons ainsi une connaissance approfondie des aspects pratiques des croisades (How to Plan a Crusade: Reason and Religious War in the High Middle Ages, Londres, Penguin Books, 2016), une analyse pénétrante du concept et de l'histoire des croisades en Angleterre (England and the Crusades: 1095-1588, Chicago, Chicago University Press, 1988), une remise en cause du concept même de croisade (The Invention of the Crusades, Basingstoke/ Londres, Macmillan, 1998) et un survol magnifique de la totalité des croisades (God's War: A New History of the Crusades, Londres, Allen Lane, 2006). On ne peut qu'être heureux qu'il continue à nous éclairer et à nous instruire. Le présent volume présente un hommage bien mérité à une œuvre d'une telle étendue. En réunissant onze articles groupés largement autour du thème de l'Europe et des croisades, ce recueil nous offre une riche gerbe de perspectives et une réévaluation d'idées reçues.

On y retrouvera des thèmes communs qui répondent à ceux développés au cours de ses travaux par C. Tyerman. Une appréciation généreuse par son 
collègue Toby Barnard nous en explique les grandes lignes (et nous rappelle aussi l'enthousiasme de C. Tyerman en tant que collègue et tuteur : qu'est-ce que c'est que cette histoire de chaises empilées qu'il aurait escaladées?!). C. Tyerman possède une connaissance encyclopédique du Moyen Âge et des croisades, liée à une compréhension profonde de la politique aussi bien médiévale que contemporaine, où l'une peut éclairer l'autre. Son respect pour les sources et témoignages va de pair avec un scepticisme face à la spéculation mal fondée. Ce sont des valeurs qu'il a inculquées à ses étudiants, ce dont le présent volume fait preuve en rassemblant des articles si variés et bien argumentés.

L'argument dominant du recueil est l'argument central de l'œuvre de C. Tyerman : les croisades ne peuvent pas et ne doivent pas être considérées comme un phénomène distinct de la société médiévale européenne. Comme le dit Nicholas Vincent (p. 286) «Il n'existe pas - ou ne devrait pas exister - telle chose que l'historiographie-croisade». On pourrait dire que peu arrive sans précédent, et que tout a une influence quelconque sur ce qui suit. Ainsi l'origine des croisades se retrouve déjà dans des concepts et structures : le paradoxe du salut face au meurtre (John France), la perception de l'islam face à celle du judaïsme (Kevin James Lewis) et le rôle de la charité (Timothy Guard). L'influence des croisades se révèle dans des événements subséquents : sans les croisades, pas de croisade contre les Albigeois (G. E. M. Lippiatt); des conséquences pour l'Afrique du Nord... (Guy Perry). Cela ne sous-estime pas bien sûr l'innovation extraordinaire théologique et logistique que représenta la première croisade (J. France), mais la compréhension des croisades va de pair avec une compréhension approfondie de l'Europe médiévale.

D'abord, le concept de croisade ne doit pas être séparé des courants et développements de la société médiévale : au contraire, les deux sont étroitement liés (et ont même des résonances modernes). J. France nous rappelle comment le message d'Urbain II à Clermont fut fondé sur la simple justification de salut pour le meurtre par le moyen d'un message court et puissant répété sans fin. Cela refléterait plutôt les exigences d'un temps de violence qu'une théologie bien considérée. T. Guard nous donne une analyse de l'importance de la caritas non seulement spirituelle, mais matérielle dans le financement des croisades, soit un «crowdfunding» médiéval, et nous déploie ainsi un panorama de l'importance de la charité dans la société médiévale. N. Vincent fournit une analyse détaillée d'un morceau de "fausses nouvelles» médiévales à Burton Abbey au XIII ${ }^{\mathrm{e}}$ s. qui renferme entre autres Joachim de Flore, une vision multicolore de la Trinité et un avenir apocalyptique. Ces articles nous montrent - comme nous l'a montré C. Tyerman - que la croisade ne se sépare pas de la société médiévale, au contraire, elle en fait partie intégralement.

Deuxièmement, on nous rappelle l'importance de l'imaginaire pour notre compréhension de la perception de croisade, soit médiévale, soit moderne. Peter Edbury nous explique comment Ernoul a introduit dans sa traduction de Guillaume de Tyr un chevalier vert quasi arthurien, qui devient dans l'œuvre illustrée de Sébastien Mamerot une figure dominante. La fantaisie sert comme moyen de déjouer la triste réalité de croisade dans un $\mathrm{XV}^{\mathrm{e}} \mathrm{s}$. sous la menace ottomane. Dans un article riche et fascinant, K. J. Lewis distingue la perception de la circoncision en tant que coutume juive et coutume musulmane : la circoncision juive, vue comme parallèle à la Crucifixion, nous rappelle le rôle qu'auraient joué les juifs selon les croyances médiévales dans la mort du Christ; la circoncision musulmane, vue comme parallèle au baptême, symbolise le danger présent et vivant au christianisme que représenterait la foi musulmane. Edward Peters examine l'image que nous donne Dante de son aïeul Cacciaguida, martyr et croisé, qui sert comme symbole d'une Florence antérieure meilleure et plus pure que la Florence de l'ère de Dante : l'image de la croisade et celle de Florence sont mêlées ainsi que le passé et le présent, et la croisade sert de chemin qui mène au Paradis.

Troisièmement, nous voyons l'importance d'une compréhension minutieuse des réalités de la vie médiévale pour comprendre leur influence sur la croisade. C'est ce que nous font voir de différentes façons Helen Nicholson dans une étude minutieuse et fascinante des comptes des maisons des Templiers : connaissait-on par ex. la hiérarchie des salaires des travailleurs agricoles ou ce qu'ils mangeaient l'été et l'hiver? L'analyse de H. Nicholson nous montre jusqu'à quel point les entreprises des Templiers ont influencé l'économie médiévale. Dans son étude des chanoines de Saint-Victor, Jessalynn Bird nous explique comment, considérés souvent comme théologiens avant tout, ils jouaient également un rôle important et peu connu en prêchant la croisade et en soutenant les croisés. Ces articles nous donnent non seulement une compréhension approfondie des croisades mais éclairent vivement la trame du menu détail de la société médiévale, comme l'a fait également $\mathrm{C}$. Tyerman dans son analyse de la logistique de croisade. 
On y retrouve enfin une mise en relief du rôle des croisades en tant qu'entreprise qui s'étend dans toute l'Europe où une perspective plus large nous amène à revisiter des idées reçues. G. Perry situe la croisade abortive de saint Louis à Tunis non pas dans les ambitions frustrées de Charles d'Anjou, mais dans une perspective bien plus large de relations économiques et d'espérances déçues de conversion entre l'Europe et l'Afrique du Nord, où l'Afrique du Nord servirait comme plaque tournante entre la réussite de la Reconquista européenne et l'échec de Jérusalem. G. E. M. Lippiatt réexamine les relations entre la cinquième croisade et la croisade contre les Albigeois et montre que, loin d'être deux croisades différentes, elles ont des participants et des thèmes de sermon en commun et se sont mutuellement renforcées. C'est un chemin qu'a frayé $\mathrm{C}$. Tyerman dans son étude des croisades et l'Angleterre : la croisade a été un phénomène à travers toute l'Europe.

On finira par une triste constatation. Ce volume renferme ce qui sera peut-être le dernier article à être imprimé de Mark Whittow, qui a trouvé une mort tragique et prématurée dans un sinistre accident d'automobile en 2017. M. Whittow revient à l'hypothèse d'Henri Pirenne selon laquelle l'Islam marquerait la fin de la civilisation romaine. Il nous propose que l'Occident a retenu une image archaïque du Proche-Orient qui explique l'approche coloniale qu'ont prise les croisés dès leur arrivée dans un pays qu'ils avaient cru habité par leurs semblables mais où ils ont trouvé en fait des chrétiens indigènes et différents. Bohémond aurait pu établir son royaume à Antioche suite à l'emploi de guerriers occidentaux dont les empereurs byzantins avaient pris l'habitude. La croisade devient alors non pas seulement question de conquête territoriale mais de reconquête du passé. C'est une analyse nuancée et brillante qui sert à nous faire regretter la perte d'un savant avec une connaissance profonde du Moyen Âge et un talent rare et prodigieux pour nous l'expliquer.

Carol SweEtenham Université de Warwick/Royal Holloway College, Université de Londres 